\title{
BUILDING A DMU E-BIOLOGY RESOURCE FOR HEALTH SCIENCES' STUDENTS
}

\author{
A. Peña-Fernández ${ }^{1}$, T. Sgamma ${ }^{1}$, C. Young ${ }^{1}$, M.J. Randles ${ }^{1}$, C. Del Águila ${ }^{2}$, C. \\ Hurtado $^{2}$, M. Evans ${ }^{1}$, N. Potiwat ${ }^{1}$, F. Izquierdo ${ }^{2}$, M.A. Peña ${ }^{3}$, J. Coope ${ }^{4}$, M. \\ Armstrong $^{4}$, A. Bhambra ${ }^{1}$ \\ ${ }^{1}$ School of Allied Health Sciences, De Montfort University (UNITED KINGDOM) \\ ${ }^{2}$ Facultad de Farmacia, Universidad San Pablo CEU (SPAIN) \\ ${ }^{3}$ Departamento de Ciencias Biomédicas Universidad de Alcalá (SPAIN) \\ ${ }^{4}$ Postgraduate and CPD Office, Faculty of Health and Life Sciences, De Montfort University
}

(UNITED KINGDOM)

\begin{abstract}
The BSc Biomedical Science (BMS) programme at De Montfort University (DMU, Leicester, UK) is accredited by the Institute of Biomedical Science (IBMS). Students enrolled within this programme acquire highly sought after skills related with human health sciences to work in: pathology departments in hospitals; research institutions; biotechnology and pharmaceutical industries and the education sector to name a few. The degree recruits a large number of students with currently around 600 students enrolled on this programme at DMU. Despite pre-entry requirements of knowledge of subjects related to human biology, biology or chemistry, we have noted that first year students require basic support in STEM subjects (biology, chemistry and mathematics) in modules such as "Basic Microbiology", "Basic Anatomy and Physiology" and "Chemistry for the Biosciences". This support is especially necessary for students that come from non-traditional routes such as Business and Technology Education Council (BTEC) routes. Moreover, usually topics related to microbiology and human diseases are challenging for students, often causing stress and impacting their overall performance and experience. A group of BMS academics at DMU in conjunction with universities in the European Union (EU; e.g. University of San Pablo CEU, Spain) have started to design, create and develop a series of e-learning resources or units in human biology and BMS for undergraduate students that study health sciences degrees in the EU. These units are being uploaded onto the DMU web server (http://parasitology.dmu.ac.uk/ebiology/home.htm) and will be only accessible for students from participating universities during the first phase of this project (2017/18 course) in which comprehensive feedback will be collected. This web server space has three sections or modules (theoretical section, virtual laboratory and microscope), in which the new e-learning resources will be initially accommodated. These units will be interactive and easy to follow, and will cover basic human biology (e.g. cells, cell structure), human anatomy and physiology, histology and basic microbiology, which will be embedded in a theoretical module named DMU e-Biology within the above URL link. The units will include formative assessments and case studies throughout each unit. In addition, a series of practical units are being developed which describe routine practical elements in any biomedical laboratory such as laboratory materials, pipetting, molecular techniques (e.g. PCR), cell culture (e.g. use of biological safety cabinet) and histological techniques (e.g. use of microtome, staining techniques). The development of this teaching and learning resource will cover a gap in the traditional teaching and learning methods that are currently used and provided in the participating universities. The DMU e-Biology package will aid to our undergraduate students to gain knowledge in human biology and microbiology by promoting self-learning. We consider that the DMU e-Biology will help overcome spatiotemporal, equipment and resource barriers. Additionally, it may help student retention as currently about a $7 \%$ of our first year students fail to continue BMS at DMU. Finally, the creation of DMU e-Biology will also provide support to the DMU Student Retention and Attainment Strategy 20162020 through the DMU Student Learning Hub, which is currently under development.
\end{abstract}

Keywords: teaching biomedical science, e-Biology, human biology, microbiology, virtual learning, undergraduate students.

\section{INTRODUCTION}

Students graduating from the BSc Biomedical Science (BMS) programme at De Montfort University (DMU, Leicester, UK), which is accredited by the Institute of Biomedical Science (IBMS), go on to 
pursue careers in a range of different sectors such as pathology departments in hospitals, research institutions, biotechnology and pharmaceutical industries, education and other areas [1]. These opportunities make BMS degrees popular; thus, approximately 600 students are currently enrolled in our programme at DMU.

University students in their first year University face a myriad of challenges such as information overload, poor individual attention and/or minimal interaction with their peers [2], which can impede their progress through higher education. These challenges, together with other factors, have an impact on student retention and progression that needs to be addressed. The literature suggests different strategies to provide students with the necessary tools to enable them to make the transition from further education to university studies. These strategies should facilitate students in the development of the necessary skills to become independent learners, as students in higher education require independence to succeed [2,3]. Thus, DMU offers a range of initiatives directed to improve students' self-confidence, inclusivity, academic and social engagement, as well as different student support programmes including a robust Disability Enhancement Programme. The support for retention that DMU offers has been highlighted in the recent UK Government's Teaching Excellence Framework (TEF), in which DMU achieved a Gold rating in 2017 [4].

Specifically for our BMS programme at DMU, we established a range of strategies in 2016/17 to improve retention and progression of new BMS students, including an intensive induction week with social and networking events with academics to enhance the development of constructive relationships. According to the data that we have to date, a small reduction in the percentage of new students that abandon their studies after their first year has been observed from 2015/16 (10.3\%; 24 students) to $2016 / 17$ (6.5\%; 13 students) [data collected from the DMU reporting software, Tableau ${ }^{\circledR}$, on 24/09/17].

However, we have noted that our BMS students require basic support in STEM subjects (biology, chemistry and mathematics) despite having met university-set entry requirements. This support requirement is frequently evident in those students that come from non-traditional routes such as Business and Technology Education Council (BTEC) routes. Additionally, the first year modules related to microbiology and chemistry/biochemistry are particularly challenging for our students, often causing stress and impacting their overall performance and experience. To address these limitations, a group of BMS academics at DMU in conjunction with the University of San Pablo CEU (USP-CEU, Spain) have started to develop a complete eLearning package, designed to enhance learning and under-pin the fundamental concepts of biology.

\section{METHODOLOGY}

The aims of this study were to describe the design, structure and preliminary development of the future DMU e-Biology resource. Details about how this novel package will be validated/tested are provided.

\subsection{DMU e-Biology}

The development of the novel DMU e-Biology package started in the summer of 2017 and will cover the specifications for AS and A level described by the Assessment and Qualifications Alliance (AQA, 2017) for human biology [5]. The final package will be publicly available at the DMU website here http://parasitology.dmu.ac.uk/ebiology/home.htm late in 2019 (Fig. 1), when comprehensive feedback from students collected during $2017 / 18$ has been addressed. 


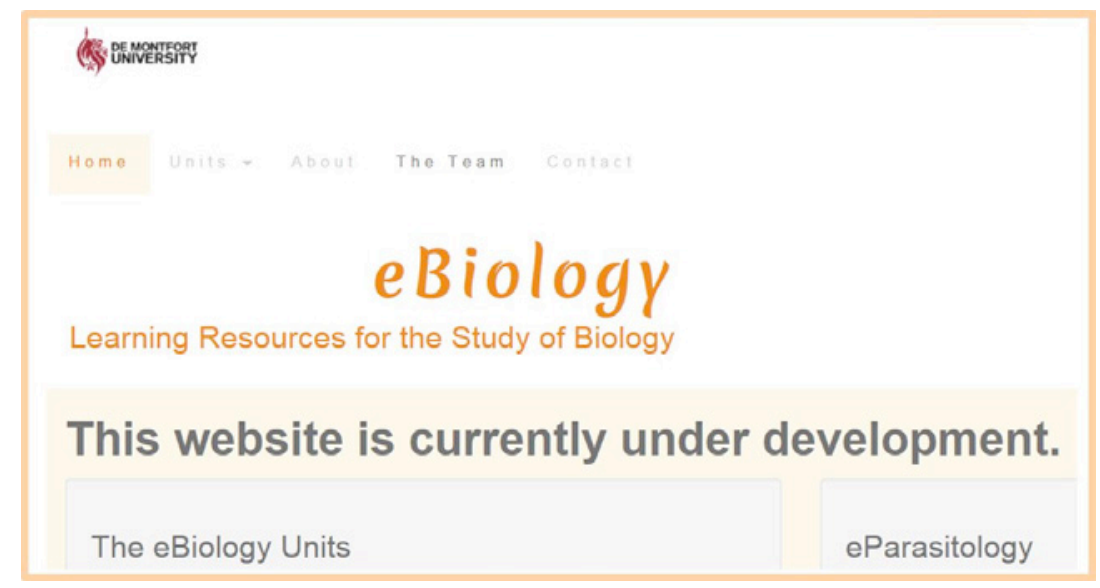

Figure 1. Overview of the main page of the future DMU e-Biology (Image courtesy of DMU; PeñaFernández et al., 2017). Available at: http://parasitology.dmu.ac.uk/ebiology/home.htm

The methods used to develop this eLearning are similar to those described by Peña-Fernández et al. (2017) to develop the DMU e-Parasitology. Two DMU developers and an artist are collaborating with academics and biomedical scientists registered by the Health Care Professions Council (HCPC) at DMU and USP-CEU in the development of this novel eLearning package. A highly skilled student studying Graphic Design at DMU was hired as an artist through a frontrunner internship for the current academic course 2017/18. The DMU Frontrunner scheme is a specific programme that facilitates the acquisition of transferable skills to DMU students that will benefit their future career [6]. Artworks, graphic designs and visual media such as interactive videos are being created by our frontrunner with support from the academics involved in this project. The use of these materials (Fig. 2) are critical to develop appropriate and engaging eLearning to facilitate understanding and enhance knowledge transfer/retention, facilitate student engagement, aid students in visualising model-based reasoning and to simplify the communication of complex biological concepts.

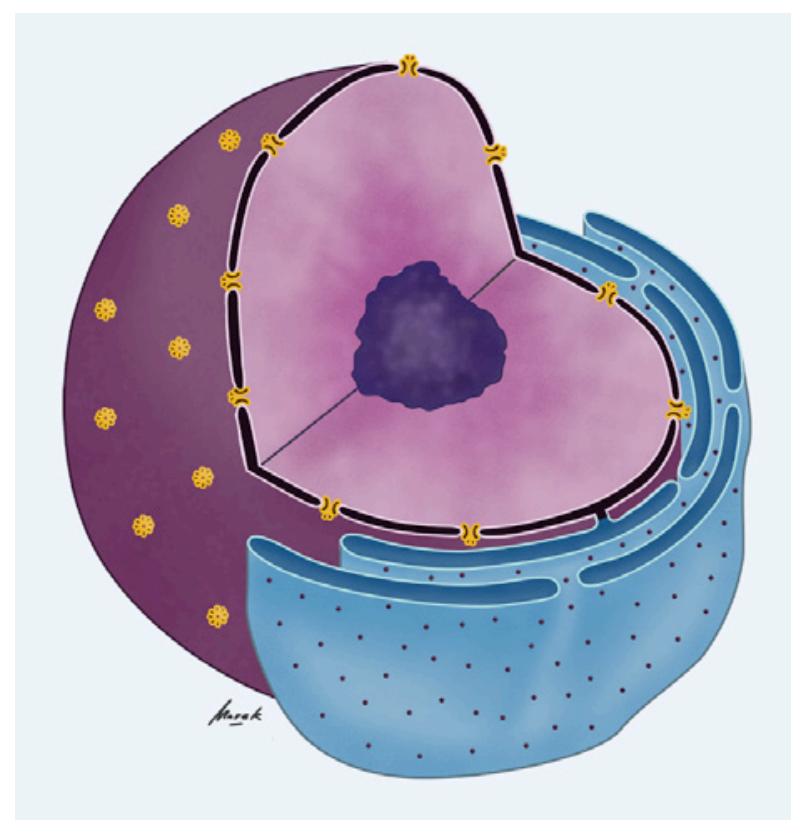

Figure 2. Detail of a draw developed by Marek Kowalic (DMU frontrunner) for the DMU e-Biology website.

\subsubsection{Sections of the DMU e-Biology package}

The DMU e-Biology package is being created using the Articulate 360 software and will have two sections or modules (Fig. 1): 
$\checkmark \quad A$ theoretical module with one mini e-learning unit for each item of core content according to the specifications for AS and A level described by AQA (2017). The units will be related to the study of human biology specifically, so core content described for the subject of biology for animals or plants have been discarded. The DMU e-Biology units will also cover the basic concepts delivered in our first year modules on Biochemistry and Cell Biology, Basic Microbiology for Biomedical Science and Basic Anatomy and Physiology. To do this, a core content unit in microbiology has been planned and will be included in the DMU e-Biology package. All units will include one or two formative assessments so that students will be able to assess their individual learning progress. This section will also have two or three units related to a case study to encourage self-learning and autonomous work on the part of the user. Case studies will be related to topics of interest for our students, such as alcohol abuse and biomarkers of disease in clinical samples. The main aim of the virtual case studies is to facilitate the development of students' abilities to critically evaluate and use evidence from the literature, skills that are invaluable to any scientist, and indeed key for future generations of biomedical scientists. A description of the core content and some details about the topics treated in each unit is described in Table 1.

Table 1. Core content and content specifications of the theoretical units of the future DMU e-Biology.

\begin{tabular}{|c|c|}
\hline Core content & Content specifications (some details) \\
\hline \multirow{2}{*}{ Brief introduction to biology } & Classification \\
\hline & Variety of living organisms \\
\hline \multirow{2}{*}{ Chemistry } & Carbon \\
\hline & Biological molecules \\
\hline \multirow{5}{*}{ Cells } & Types \\
\hline & Cell structure and membrane \\
\hline & Cell components \\
\hline & Proteins and enzymes \\
\hline & Mitosis and meiosis \\
\hline Cellular respiration & Structure and function of ATP \\
\hline \multirow{2}{*}{ Human anatomy and physiology } & Tissues and organs \\
\hline & A description of each system \\
\hline \multirow{2}{*}{ Genetics } & DNA and RNA \\
\hline & Protein synthesis \\
\hline \multirow{3}{*}{ Basic microbiology } & Archaea and bacteria \\
\hline & Infectious diseases \\
\hline & Antibiotics \& antibiotic resistance \\
\hline
\end{tabular}

A virtual microscope with a real slide collection of human and mammal cells, tissues and organs. The four functions of a light microscope (displaying, panning, zooming and focusing) will be simulated in this section using the resource Zoomofy ${ }^{\circledR}$. Students will be enabled to view any part of the slide at any magnification. Slides will be provided with informational texts, background and annotations, and activities to facilitate the students' self-learning and interaction [7]. This section is a key part of the project, as it can overcome difficulties such as the increasing number of students in practical sessions and limited resources (time and staff), the presentation of 'just' selected illustrations, the difficulty in maintaining and archiving slides, or equipment maintenance costs. 


\section{RESULTS \& DISCUSSION}

Two units have currently been developed, for the study of the human excretory and respiratory systems (Fig. 3).

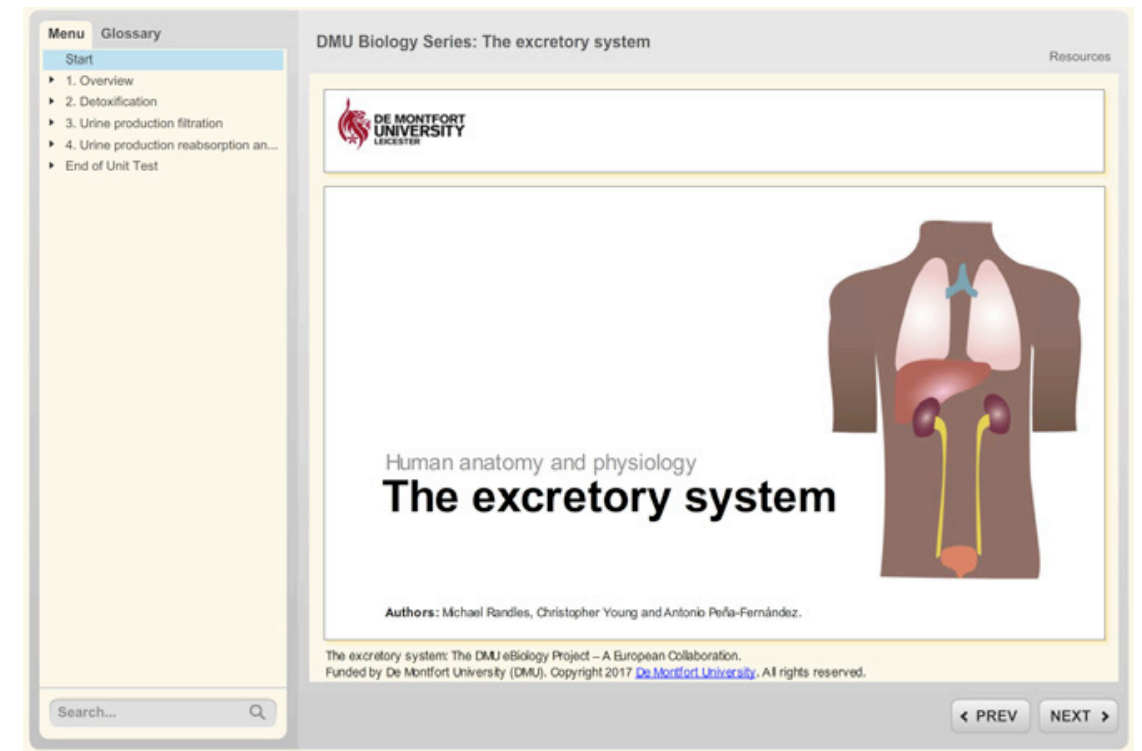

Figure 3. Overview of the main page of the unit The Excretory System in the DMU e-Biology website (Image courtesy of DMU; Peña-Fernández et al., 2017). Available at:

http://parasitology.dmu.ac.uk/ebiology/units/excretory-system/story.html

Additionally, a series of practical units are being developed which describe routine practical activities in any biomedical laboratory such as laboratory materials, pipetting, molecular biology techniques (PCR, Western blotting, etc.), cell culture and histological techniques (cutting tissue sections, staining procedures, etc.). These units will be accessible in the practical section of DMU e-Parasitology here: http://parasitology.dmu.ac.uk/learn/laboratory.htm (a hyperlink to this section in the e-Parasitology package is provided in the DMU e-Biology website).

The DMU e-Biology units developed so far will be tested during the 2017/18 academic course at DMU in different teaching environments and modules to collect comprehensive feedback. The feedback will be used to create a robust package by the end of 2018. Ideally DMU e-Biology will be accessible to students pre-course registration for the degree to enable prospective students to engage with fundamental concepts early in preparation for their course. An electronic survey with Likert and open questions will be created, similar to those developed to test DMU e-Parasitology (more information can be found in [8]). During this phase of the project, students will be able to act as co-creators of DMU e-Biology by highlighting areas in need of development and additional support and to suggest additional content for this learning resource.

\section{CONCLUSIONS}

The DMU e-Biology package, in conjunction with DMU e-Parasitology, will cover a gap in traditional teaching and learning methods that are currently exist in participating universities. The DMU e-Biology teaching resource will aid our undergraduate students in gaining significant knowledge in human biology by promoting self-learning, which may aid student retention. Furthermore, the availability of this resource prior to students starting their course may enable earlier engagement with teaching staff and resources, thus reducing anxiety levels during the most difficult transition from college to university.

\section{ACKNOWLEDGEMENTS}

The authors would like to express their sincere appreciation to Marek Kowalic (DMU frontrunner 2017/18) for his designs and videos. We would like to thank the DMU e-Parasitology project team 
[Teaching Innovation Project Fund at De Montfort University (scheme 2015-16); project lead Dr PeñaFernández] as we are partly using these resources to develop DMU e-Biology.

\section{REFERENCES}

[1] BSc Biomedical Science programme website. Available at the DMU website: http://www.dmu.ac.uk/study/courses/undergraduate-courses/biomedical-science-bsc-honsdegree/biomedical-science-bsc-hons.aspx [accessed 12/09/2017]

[2] Foy C. and Keane A. Introduction of a peer mentoring scheme within biomedical sciences education - easing the transition to university life. Journal of Further and Higher Education 2017; in press. DOI: 10.1080/0309877X.2017.1311994

[3] Colthorpe K, Sharifirad T, Ainscough L, Anderson S, Zimbardi K. Prompting undergraduate students' metacognition of learning: implementing 'meta-learning' assessment tasks in the biomedical sciences. Assessment \& Evaluation in Higher Education 2017, in press. DOI: 10.1080/02602938.2017.1334872

[4] Teaching excellence framework (TEF), 2017. Higher Education Funding Council for England (HEFCE). Available at: http://www.hefce.ac.uk/lt/tef/ [accessed 24/09/2017]

[5] AQA. AS and A-level Biology Specifications. Available at: http://www.aqa.org.uk/subjects/science/as-and-a-level/biology-7401-7402 [accessed 24/09/2017]

[6] DMU Frontrunner scheme information available at: http://www.dmu.ac.uk/dmustudents/careers-and-employability/internships/internships.aspx

[7] Brochhausen $\mathrm{C}$, Winther HB, Hundt C, et al. A virtual microscope for academic medical education: the pate project. Interact J Med Res 2015; 4(2):e11.

[8] Peña-Fernández A., Ollero MD., Fenoy S., Magnet A., Izquierdo F., Peña MÁ., Bornay F., Acosta L., Parker LA., Sgamma T., Del Águila C. Creating a model module for the novel resource DMU e-Parasitology. ICERI2017 Proceedings; accepted for publication. 